\title{
感染性人工膝関節の治療経験
}

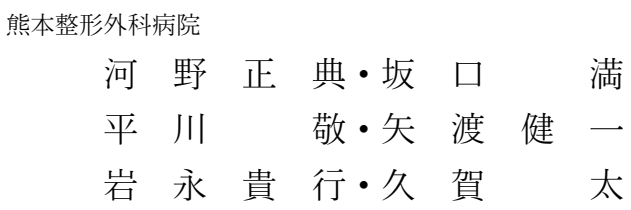

\section{Treatment for Infected Total Knee Arthroplasty}

\author{
Masanori Kawano, Mitsuru Sakaguchi, Kei Hirakawa, \\ Kenichi Yawatari, Takayuki Iwanaga, and Futoshi Kuga \\ Kumamoto Orthopaedic Hospital, Kumamoto, Japan
}

\begin{abstract}
We treated eight patients with infected total knee arthroplasties for 17 years. We reviewed the onset time of infection, organism, and timing of reimplantation. Cultures grew methicillin sensitive Staphylococcus aureus in all cases. Two joints were cured by continuous drainage and retained prosthesis, and 2-stage reimplantation was performed on six joints. In comparing knees with successful salvage to those with persistent infection, the following factors strongly correlated with successful salvage : short duration of symptoms of infection ( $<3$ weeks) and no prosthetic loosening or roentgenographic evidence of infection. In TKA complicated by infection, implant salvage with aggressive surgicai debridement and antibiotic therapy should be strongly considered, provided that these strict criteria for attempted salvage are observed.
\end{abstract}

Key words : total knee arthroplasty (人工膝関節置換術), infection (感染症), reimplantation (再置 換術)

\section{は じめに}

人工膝関節置換術（以下 TKA）後の合併症の中で 感染は重大な合併症の一つである。 今回, 我々が施行 したTKA 症例のうち術後深部感染の発症率の調查と その治療法を検討した。

\section{症例}

対象は昭和 63 年から平成 16 年 2 月までに当院で行っ た TKA1334 例中，著者らが施行した 629 例とした。 術後深部感染を発症した症例は男性 2 例女性 3 例の 5 例 5 関節である. 感染発症時年齢は 45 歳から 83 歳で 平均 67 歳であった。基礎疾患は变形性膝関節症が 3 例，関節リウマチが 2 例であった。抗菌薬の投与は術
前に塩酸セフォチアム（以下 CTM） $1 \mathrm{~g}$ 投与し, 術 後は CTM $2 \mathrm{~g}$ を 5 日間投与していた。これらの群に おいて感染発症時期, 起炎菌, 治療方法などを検討し た.

\section{結果}

著者らが施行した TKA 術後の深部感染率は $0.8 \%$ であった。全例初回手術後の感染であった。手術後 3 ケ月以内を早期感染， 3 个月以上を遅発性感染とする と, 全例遅発性感染であった。起炎菌は全例メチシリ ン感受性黄色ブトゥ球菌（以下 MSSA）であった。 全例とも感染徴候が現れてからす心゙て 3 週間以内に抗 生剂投与, 洗浄, 病巣掻爬, ドレナージを行い, イン プラントの温存を試みた。このうち 2 例はインプラン 
卜を温存できたが 5 例は感染の沈静化が得られずイン プラントを抜去し， 2 期的再置換術を行った。現在の ところ全例 1 本杖にて歩行を行っている.

\section{症 例 提 示}

症例 $1: 75$ 歳, 男性. 平成 5 年 9 月, 右変形性膝 関節症に対しインターラックス型人工膝関節にて右 TKA を施行した。平成 6 年 9 月 7 日，発熱拉よび右 膝の疼痛, 発赤を認めた。炎症反応の上昇がみられ， $\mathrm{CTM}$ 投与を開始した。感染発症時期の X 線をみると (図 1)，ZONE 1 に radiolucent line を認めるが全周 に及ぶ明らかな loosening はみられなかった。 9 月 8 日，右膝滑膜切除術抢よびドレナージを開始した。 8 日後，CTM からホスホマイシン（以下 FOM）へ変 更した。 11 日後, 局所所見, 炎症反応上り沈静化し たと判断し，ドレーンを抜去した。感染寛解期の X 線では（図 2), clear zone は認められない。現在, 感染症の再熱は認められず，1本杖にて歩行中である. 症例 $2: 73$ 歳, 男性. 平成 3 年 2 月, 関節リウマチ に対し MARK IIIにて左TKA を施行した。平成 10 年 7 月 27 日, 発熱执よび左膝の疼痛, 発赤を認め, 卜 シル酸スルタミシリン（以下 SBTPC）の投与を開始 し, 左膝滑膜切除抢よび持続洗浄を開始した。この時 期の X 線像である（図 3 ）。 8 月 10 日持続洗浄チュー
ブを抜去した。9月 28 日，再び発熱扔よび右膝の疼 痛, 発赤が出現したため, インプラントを抜去し，七 メントスペーサーを挿入した（図 4 )。CTM 投与を 開始し，途中でより感受性のあるスルバクタムナトリ ウム・セフォペラゾンナトリゥム (以下 $\mathrm{SBT} / \mathrm{CPZ}$ ) へ変更した。平成 10 年 10 月 20 日, Nexgen LPS に て左 TKA 再置換術施行した（図 5 )。現在は感染症 の再燃は認められず，1本杖にて歩行している.

$$
\text { 考察 }
$$

人工膝関節術後の深部感染症ではインプラントを抜 去し 2 期的再置換を施行することで感染の沈静化が得 られたという報告2)576) が多く見られる。しかし， Burger $~^{1)}$ は，人工膝関節術後の深部感染症例のう ち, 適応症例を厳密に選択することで洗浄, debridement, 抗生剂投与により感染の沈静化が得ら れ，インプラントの温存が可能であると述べた。 TKA の感染例に対しインプラントを温存が可能な症 例は，1）感染徵候がみられて $2 \sim 3$ 週以内，2） loosening がみられない， 3 ) MRSA 以外のグラム 陽性球菌で感受性のある抗生剤が存在する，4）sinus tract がない，以上の条件を満たすむのであると 述べている. Silva ら ${ }^{4)}$ も同様の報告を行っている. Schoifet $ら^{3)}$ (感染症状発症加 21 日以内に治療を
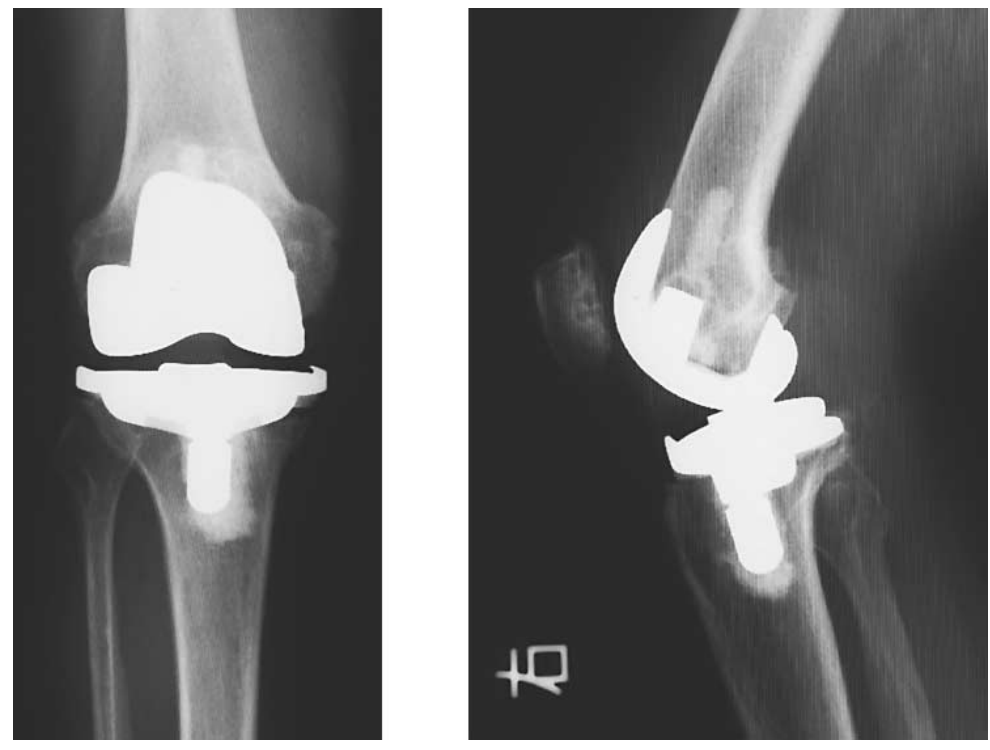

図 1 : 全周性の radiolucent line はみられない. 

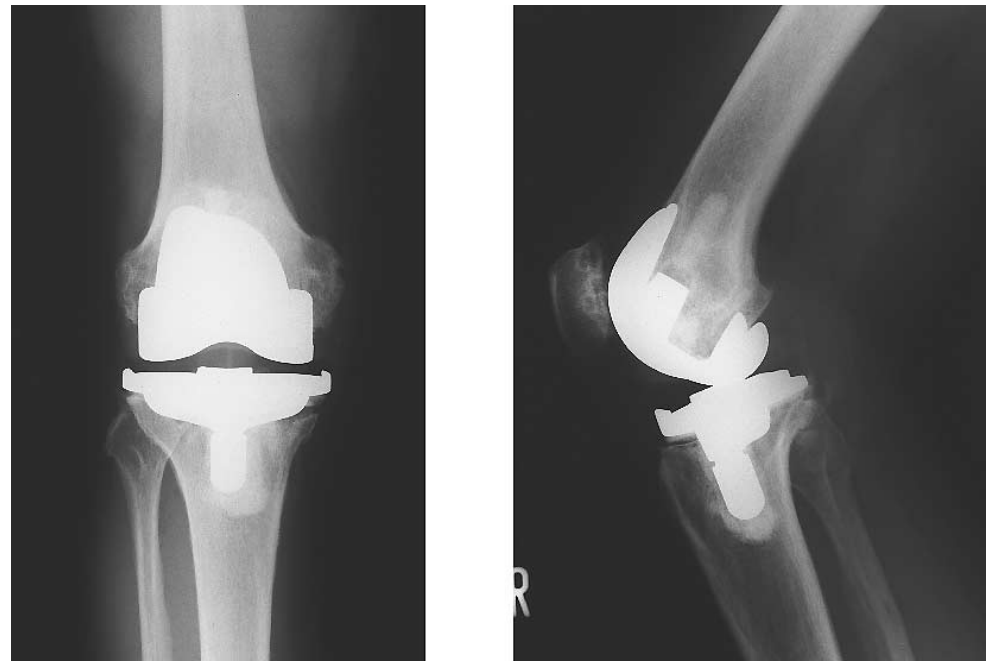

図 2 : 感染症の再燃はみられず経過良好である.
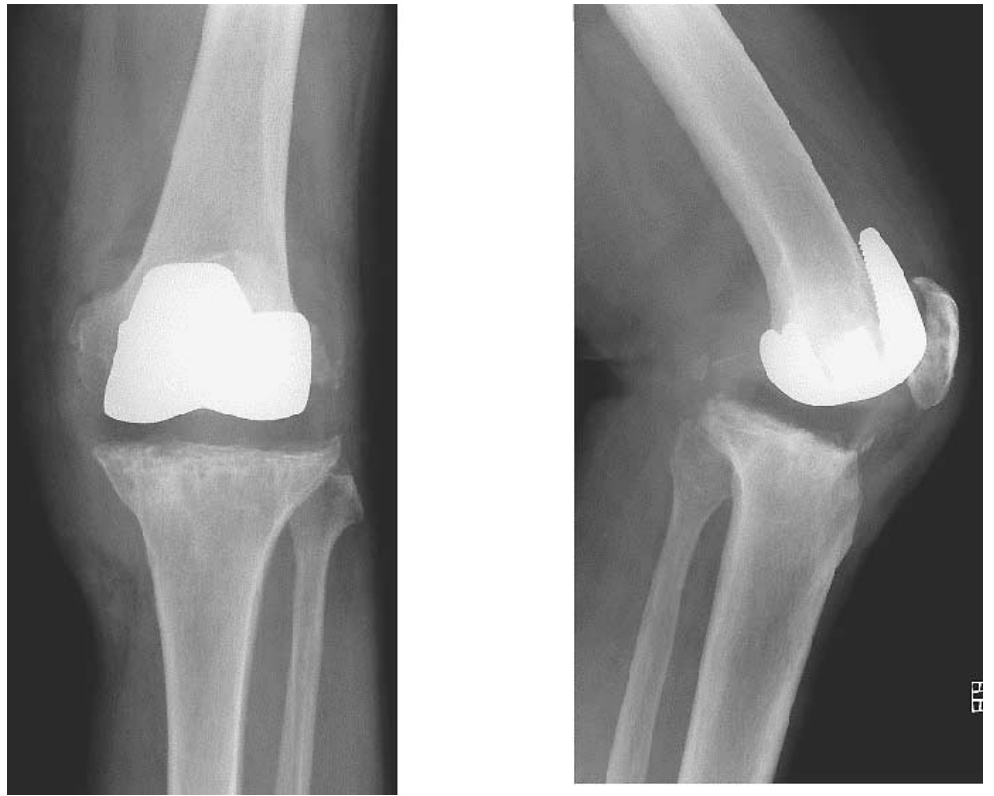

図 3：明らかな loosening はみられない.

開始した症例はインプラントの温存が可能であり, 成 績良好であったとしている.

我々の考える感染性 TKA 症例に対する治療方針を 示す (表 1 ). 感染徵候から 3 週以内で loosening が 認められず，かつ明らかな骨䯣波及が見られない症例 に対しては人工関節を抜去するのではなく，まず徹底
的な病巣掻爬とドレナージおよび持続洗浄にて感染の 沈静化を試みる. 感染徵候から 3 週以上経過している, loosening がみられる，骨髄波及が認められるという 症例に対しては人工関節を抜去し 2 期的再置換術を行っ ている。 今回，われわ机は文献扔上び当院における治 療方針に基づいた方法で感染症の沈静化を得た。 

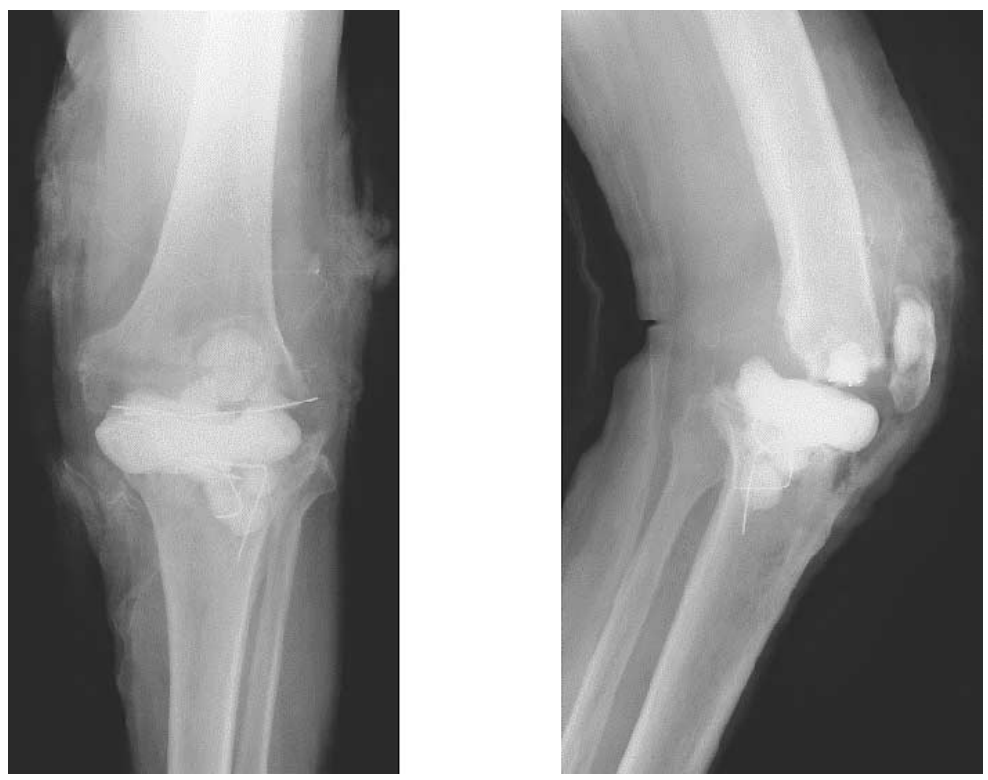

図 4 ：インプラントを抜去し, セメントビーズを挿入した.
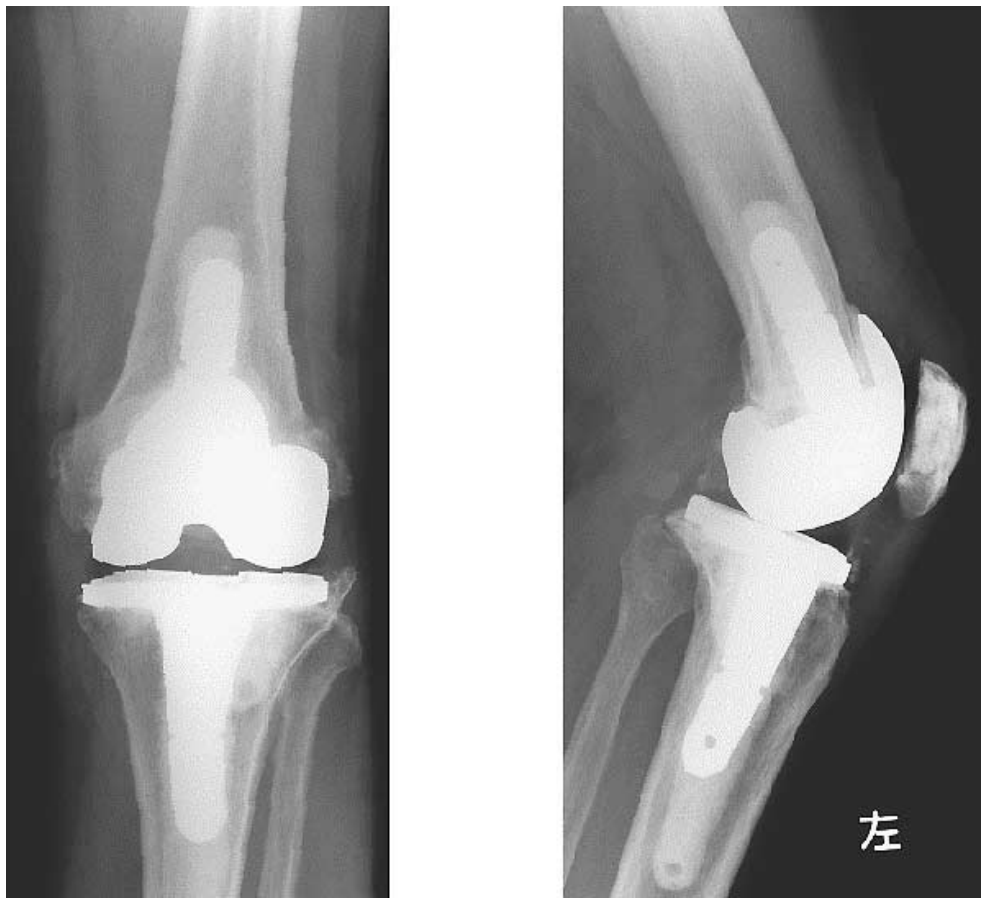

図 5：2 期的再置換術を施行し，経過良好である. 
表 1 ：当院に抢ける T K A感染症例に対する治療方針

\section{-感染症状発現から3週間以内 \\ -Looseningが認められない \\ ・明らかな骨髄への波及が認められない}

$\downarrow$

病巣掻爬、洗浄、

ドレナージ(持続洗浄)
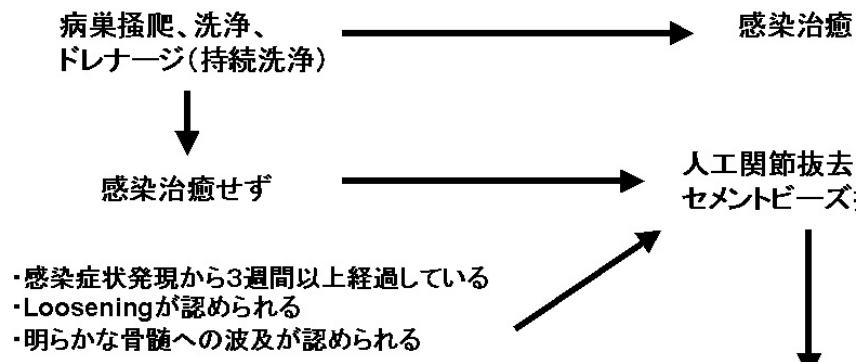

ま と め

1 ）我々が行った TKA 術後の深部感染率は $0.8 \%$ で あった。

2 ) 症状発現から 3 週以内の症例, loosening を認め ない症例，また明らかな骨䯣への波及がみられない 症例に対してインプラントの温存を選択した。

3 ) 以上の条件を満たさなかった症例に対しては 2 期 的再置換術を行った。

4) 7 例 7 関節全例に感染症の沈静化が得られ, 術後 平均 4.1 年経過した現在も再燃はみられない.

\section{参 考 文 献}

1) Burger, et al. : Implant Salvage in Infected Total

Knee Arthroplasty. Clin. Orthop., 273 : 105-112, 1991.

2) Russell, E. W., et al. : Two-Stage Reimplantation for the Salvage of Total Knee Arthroplasty Complicated by Infection. J. Bone Joint Surg. Am., 72(2) : 272-278, 1990.

3) Schoifet, S. D., et al. : Treatment of Infection after Total Knee Arthroplasty by Debridement with Retention of the Components. J. Bone Surg., 72(9) : 13831390, 1990.

4) Silva, et al. : Results of Direct Exchange or Debridement of the Infected Total Knee Arthroplasty. Clin. Orthop., 404: 125-131, 2002.

5) Whiteside, L. A. : Treatment of Infected Total Knee Arthroplasty. Clin. Orthop., 299 : 169-172, 1994.

6) Wilde, A. H. : Two-Stage Reimplantation in Infected Total Knee Arthroplasty. Clin. Orthop., 236 : 23-35, 1988. 